\title{
Nabokov's Postmodernism: The Matter of Discourse and Survival in Pale Fire
}

\author{
Pyeaam Abbasi \\ English Department, Faculty of Foreign Languages, University of Isfahan, Hezar Jerib St., Isfahan, Iran \\ Omid Amani \\ University of Isfahan, Isfahan, Iran
}

\begin{abstract}
Postmodernist fiction, Brian McHale believes, is always about death. Nabokov's Pale Fire (1962) as an allegory of death and writing is about John Shade's poetic meditations on life and death. The present study is an attempt to explore the relationship between death and writing by applying McHale's theory to Nabokov's novel to show how life is equated with discourse, and death with the end of discourse and silence. The two author-figures-Shade and Kinbote—struggle to continue their narration(s) by reconstructing their selves through and into language, for they know that end of discourse brings their nonexistence. Ontologically speaking, Kinbote who can be Shade the poet provides the reader with a long commentary on Shade's poem, and extends his narration in order to delay fate and remain alive.
\end{abstract}

Index Terms-McHale, Nabokov, Pale Fire, discourse, survival, death

\section{INTRODUCTION}

In most of the postmodernist novels death is dealt with in one way or another. Nabokov's Pale Fire (1962) as a postmodernist piece of writing is no exception. Brian McHale in his influential book Postmodernist Fiction (1987) goes further to conclude that postmodernist fiction is "always about death" because "death is the one ontological boundary that we are all certain to experience" (p. 231) or to quote Ong "death inhabits texts" (1977, p. 231). Sharpe believes that "the theme of death is directly linked to various motifs of revolutionary-utopian attacks on culture and humanism." He continues that death proves to be "an integral image of the dark, unrecognizable and horrifying chaos from which even the creative act is no protection" (1999, p. 116). Death is of high interest to Nabokov and his novel has been read as an allegory of death and writing. The novel is also one of discovery abound with uncertainties, wordplay and allusions, and above all an exploration of death which to Nabokov was "a means of establishing limits-between life and death, fiction and reality, text and self' (Boyd, 1983, p. 162).

Foregrounding of the literary techniques or different ontological boundaries is an undistinguishable feature of a postmodernist novel, and a foregrounding that cannot be ignored in Pale Fire is that of the relationship between death and writing. The present study is an attempt to explore the relationship in detail taking into consideration McHale's point that "life is equated with discourse, death with the end of discourse and silence." Ipso facto, existence depends on the act of narration or "continuing to tell stories" (1987, p. 228).

The equation of life with discourse and writing means that it is fear of death that keeps the story of Kinbote with his "fantastic relocation of a thoroughly realistic poem" (Boyd, 1999, p. 47) going on in the novel. What will be discussed is the fact that through narration and providing the reader with such a lengthy and sometimes impertinent commentary, Kinbote tries, to quote Sukenick, to "filibuster ... fate" (1969, p. 55) and prolong his existence. By providing the reader with such a commentary the source of which is his imagination-Maddox believes there is also a second source and that is "Kinbote's agonizing sense of loss; while we are never exactly sure what he has lost, it is clear that he not only wants but needs to return to the past and reconstruct it" (2009, p. 16)-Kinbote continues the narration in order to transcend death, for he knows silence equates death and no wonder Shade who can be Kinbote himself is shot after placing his unfinished "poetic meditations on life and death" (Morris, 2010, p. 53) on the shelf. What Kinbote wishes to do is reconstruction of his self through language and capturing an identity other than Charles. Maddox believes that "Kinbote's belief in the literally life-giving and life-sustaining power of art is a function of his need to establish a satisfying version of his own identity" (2009, p. 18).

Waugh states that "postmodernism represents the dissolution of the self into language" and Kinbote desires to dissolve his self into his writing to create a new identity, evade Shade's fate, and filibuster his own death. What Kinbote does is creation of a long commentary which is an attempt to "articulate" his "subjectivity" (1992, p. 64) and fix himself in the narration. As a refugee from death, Kinbote seeks a shelter-New Wye - and a new identity to be confirmed through his self-conscious act of narration and commenting on Shade's poem. The Foucauldian relationship between writing and death is a dominant theme in Russian metafiction. Foucault believes that "the conception of spoken or written narrative as a protection against death has been transformed by our culture." He continues that "writing is now linked to sacrifice and to the sacrifice of life itself ... where a work had the duty of creating immortality, it now attain s 
the right to kill, to become the murderer of its author" (2000, p. 175) which signifies that the narratives formed by both Shade and Kinbote are sure to bring them death.

\section{SHADE'S DiscouRSE}

The author, in McHale's words, is "a plural" (1987, p. 200) and what can be perceived in Pale Fire is a distribution of Nabokov that gives birth to the two figures of Shade and Kinbote located at different ontological levels in the novel. One hypothesis regarding Shade and Kinbote is that Shade's poem is Kinbote's biography and Kinbote is Shade himself commenting on the poem to continue the narration and go beyond death. In this case Shade's poem becomes a means of Kinbote's survival. What is noteworthy here is Shade's obsession with the idea of death. Lines 173 through 176 read: "There was the day when I began to doubt / Man's sanity: How could he live without / Knowing for sure what dawn, what death, what doom / Awaited consciousness beyond the tomb?" Having experienced his parents' and daughter's deaths, Shade is much concerned with "a time when I am not alive" and tries "to imagine your nonexistence" (Hofstadter, 1980, p. 698).

The obsession pushes Shade into writing his poem which becomes a means of experiencing death by getting in touch with what has occupied his mind for a long time. Therefore, the poem changes into a quest, a "lifelong quest to discover what lies beyond the self, especially in the ultimate, all-resisting secret of death, and to make what he can of life in the face of the uncertainty of death" (Boyd,1999, p. 71). Thus, if Shade and Kinbote are ontologically not taken as two different figures, the poem becomes the starting point of a narration which is continued by the commentary resulting in Kinbote's extension of life. Lines 177 through 179 read: "And finally here was the sleepless night / When I decided to explore and fight / The foul, the inadmissible abyss [of death]." Shade lost his parents, lost his daughter, and now, out of fear of losing himself starts composing the poem. Shade or the egotistic Kinbote obsessed with the idea of death has had a near-death experience and starts composing his poem to protect and immune himself against it. Poetry in Shade's hands changes to a weapon by which he tries to conquer death and shape it into his own language-discourse of survival.

At the close, Shade sets his unfinished poem back on the shelf awaiting the sunset. The silence turns the sunset into the sunset of his life making the end of his narration the end of his existence. Shade, then, becomes projected into Kinbote who has to continue the discourse if he wishes to stay alive. Boyd believes that "Kinbote has been feeding Shade the story of the king" (1999, p. 21) and the poem is Kinbote's story to be continued by himself in the commentary.

Shade, being obsessed with the idea of his daughter's suicide and his own mortality, composes his poem based on death and this motif foreshadows later events. Shade has been struggling to understand life and death, life and the hereafter, life and what may lie beyond it. His attempt is reflected in the opening lines of the poem where he is likened to "the waxwing" flying into "the false azure in the windowpane; ... in the reflected sky" (11. 1-4). The waxwing seems weak for the window reflecting the sky which indicates what lies beyond life. Shade in these lines projects himself, imaginatively, into the waxwing, as if it were still flying beyond death and into the reflected azure of the window, as if that were the cloudlessness of some hereafter, even as he stands looking at "the smudge of ashen fluff" of the dead bird's little body. These opening lines suggest that Shade's poem is going to be an evasion of the hereafter, or an exploration of death. Vera Nabokov states that the "principle theme of Nabokov's work [is] the hereafter" (Pifer, 2003, p. 8).

The death motif introduced in canto one continues into canto two where Shade begins his quest of "the inadmissible abyss" while he knows that he cannot be paying-off in his quest of finding out about death and he is helpless in his confrontation with the mystery of death which foreshadows his own death. Shade knows that his poem cannot continue and will stop at a line to mark his disappearance.

In canto three, Shade who recollects memories from the past is beyond life: the canto refers to Shade's near-death experience, a vision of afterlife where life may be peaceful and a continuation of the life on earth which is again an indication of Shade's obsession with death and his desire to conquer it. Desperate in his need, Shade tries to see behind life the ability to do which comes through his art.

Canto four confirms Shade's poem as the only way of dealing with death, and poetry as the only way of understanding life. No wonder this canto begins with "now" in which Shade tries to remain. This "now" is the now of his composition which seems the only way of survival. Through his composition, Shade even realizes the harmony between sounds of the poem and the order in the world. As long as the harmony exists, Shade can live in "now:" "And if my private universe scans right, / So does the verse of galaxies divine / Which I suspect is an iambic line" (11. 975-77). Shade sets the poem on the shelf awaiting the sunset which changes into the close of his life. Failing to conquer death and before he breaks off, the only achievement seems to be, through art, the celebration of his everlasting love for Sybil and Hazel to the point that even after his death he wants to keep the memory of every detail of his life in his poem. McHale believes that "every ontological boundary is an analogue or metaphor of death; so foregrounding ontological boundaries is a means of foregrounding death, of making death, the unthinkable, available to the imagination" (1987, p. 231) which here is true of Pale Fire projecting the hereafter and making it somehow questionable through the power of imagination.

Shade's approaching the hereafter is a trespassing of ontological boundaries and he believes that "the uncertainties of death can be accounted for institutionally" (Belletto, 2006, p. 764). This signifies that Shade is after finding a way to manage death: "Institution (I) of Preparation (P) For the Hereafter (H) (1l. 503-4) is the institution in charge of exploring 
what lies in the hereafter. Shade imagines transcendence, and through art wants to manage death. By imagining, he is able to possess and control the hereafter. Linda Hutcheon refers to Humbert Humbert who can possess Lolita only imaginatively: he cries to the readers not to "skip these essential pages! Imagine me; I shall not exist if you do not imagine me" (1983, p. 122). McHale states that "postmodernist writers have attempted to imagine transcendence, filibustering fate even beyond the supposedly ultimate limit of death itself, they project discourse into death" (1987, p. 230). However, Shade is not a voice to be heard from the hereafter or from beyond the grave, and fails to extend his discourse any farther. He is unable to do anything apropos of the quality of the hereafter, to cope with, to manage such an experience and to project the poem into it. Being unable to do so he meets death where his narration has stopped.

\section{KINBOTE'S DisCOURSE}

Through fiction it is not impossible to become another self and project one's self into another being. It is not hard to imagine Kinbote as a human subject who tries to be recognized through another human subject that is Shade. Kinbote can be taken as the projection of Shade into another human subject meaning Kinbote who bound Shade to himself by first integrating himself within every aspect of Shade's life and by acting as a god of poetry to Shade to start the story of this very god of inspiration. When Shade dies, Kinbote takes control of the poem to fit his own purpose of integration on the New Wye literary circle as a way of securing a new identity in New Wye and later on his existence.

Kinbote, in desperate need of a long discourse, extends the poem by his comments just to extend his life and career. However, Kinbote is not a good poet, at least not as capable as Shade, and is "a poor reader." The narration continues in a totally different form-comments-because Kinbote is an excellent writer and "a natural storyteller full of ... invention" (Boyd, 1999, p. 74).

Through the comments Kinbote's self is shaped and in order to protect his self or new shape the "chance events" are ordered as "a casual chain" (Belletto, 2006, p. 770) so he may extend the narration as long as he can. Accordingly, Kinbote becomes paying-off in controlling both the reader and the narration. The narration is composed of the events of Zembla whose king - Kinbote - is a refugee from death and the rebels who want to assassin him. By concocting the tale of Zembla, Kinbote extends the narration and provides the reader with more than 100 pages of commentary. However, an end must be put to the commentary therefore, in his mind, Kinbote is always awaiting the arrival of a second Gradus who will "presently ... ring at my door" to equate end of his narration with his nonexistence. Kinbote concludes that as soon as his work is over and the poet in him dead, a "more competent Gradus" will not be far away to shoot the right person (Pale Fire, p. 236). What is noteworthy in Nabokov is that "the key structure is the hero's obsession" and his plots "tend to show the accumulating pattern of a single life, the whole distinctive pattern of a hero's past, the unique rhythms of his "fate," the special design of a person's individuality that extends through a life and often into the moment of death" (Connely, 2005, p. 35).

At the end of the Foreword Kinbote claims that "without my notes Shade's text has no human reality at all" and continues to affirm that the "reality" accorded to the poem is provided by "only my notes" (Pale Fire, p. 25). Waugh believes that "the fictional content of [such a metafiction as Pale Fire] is continually reflected by its formal existence as text, and the existence of that text within a world viewed in terms of 'textuality.' Waugh refers to McHale's suggestion that "such contradictions are essentially ontological (posing questions about the nature and existence of reality)" (1984, p. 15).

The words carry a touch of agitation and show that Kinbote is caught in a state of despair and horror. Too much worried about the narration, Kinbote "does not bother to trace sources in the original language, [and] fails to identify natural objects" (Boyd, 1999, p. 69). Kinbote has lost his kingdom and Gradus is on his way to take his life. Kinbote knows that the only way to stave off silence is writing and starts the commentary section which tends to become too personal and autobiographical-mainly where he suggests that he is the Zemblan king - to immortalize himself in Shade's poem. This is the reason for first, the many points in the narrative commentary being irrelevant; second, Shade's poem and its aesthetic values being ignored; third, the comments being in favour of Kinbote's interests and line of story; fourth, the idea of Hazel - a major theme in Shade-ignored in favour of Kinbote's own life and Zembla narrative and fifth, the ignorance of allusions employed with great sensitivity.

All Kinbote is after is to stave off silence, that is why in addition to providing readers with such comments, he asks the reader to read the comments over and over. The language employed by Kinbote is important in revealing his life and the related details. The language is not there to clarify Shade's poem's meanings. As a matter of fact, the intended meanings are dissolved in the discourse which is crucial to Kinbote's survival, and surprisingly the reader comes to comments on the unwritten line-1000. It is the act of narration that protects him and ensures his survival. Kinbote creates the events of commentary which at first seem accidental and impertinent, however encouraged by his own comments and mastery of manipulation he cries "I shall continue to exist ... I shall try to exist" (Pale Fire, p. 236).

\section{A WORD ON ZEMBLA}

"As soon as your poem is ready, as soon as the glory of Zembla merges with the glory of your verse, I intend to divulge to you an ultimate truth, an extraordinary secret, that will put your mind completely at rest" (Pale Fire, p. 171) are part of Kinbote's words in his comments to lines 433 and 434. Kinbote, at first, does not reveal his true identity but 
introduces another line of story-Zembla - to continue the narration. It is noteworthy how Kinbote imposes the Zemblan theme on Shade yet hiding his true identity from him. As a matter of fact, Kinbote needs the Zemblan story to be put in verse in the hands of a poet like Shade. In order to survive, the discourse must be kept going and Kinbote tries to shape Zembla into his own language. The mythical Zembla provides Kinbote with the chance for further commenting and keeping the discourse alive. The Zemblan theme explored in Shade's poem is the story of Kinbote's narration and survival. Accordingly Shade's poem is the production of Kinbote's image in the narrative of his survival. McHale believes that "the postmodernist author is even free to confront us with the image of himself or herself in the act of producing the text" (1987, p. 199). The projected fictional world of Zembla is a writerly text of Kinbote and his mythical kingdom providing the reader with Kinbote's image as the king and the whole novel as the king's narration in which a variety of ideas and events exist to ensure continuity of the narration. Kinbote can be regarded as the "postmodernist author" of the myth of Zembla in which the ontological boundaries are foregrounded.

What Boyd says seems to be a confirmation of Kinbote's success in his act of narration: Shade helps Kinbote compose the commentary from beyond the grave. Now Kinbote is beyond death, has conquered death and is in command of his narrative. As far as he is in command, a second Gradus will not appear or if appears will not be successful at shooting the right person. However, the narration is likely to end somewhere and all Kinbote is able to do now, being obsessed with the thought of Gradus, is to create an image of himself based on every detail crossing his mind. And even if the details of the story including Gradus are fantasy springing out of Kinbote's troubled mind, they add significantly to Kinbote's narration confirming the importance of Kinbote as a creative narrator keeping his discourse going. He has to avoid silence by manipulating language into shaping his story.

One of Heidegger's arguments is that "the work of art has a finite life-span" (qtd. in Clark, 2002, p. 63) which can be attributed to the life-span of every narration as well. A limited span of time and space pushes Kinbote into manipulating the discourse, the reader, and extension of his narrative. The close or the final sunset of his life is confirmed through the approaching of Gradus who will put an end to Kinbote's art. Kinbote's attempt is to extend the life-span of his narration and delay Gradus's arrival.

In a postmodernist novel such as Nabokov's Pale Fire where ontological boundaries are explored and foregrounded, it is not easy to draw lines between characters and distinguish them. Even the worlds, fictional and real, are mixed and apt to the free play of meanings. The only "real reality" seems, according to McHale, to be "writing itself" (1987, p. 198). What Nabokov has written is about the discourse(s) of two author-figures, who may not be different in identity, and introducing them into the structure of the novel. One is Shade, a poet who has seemingly composed a poem on the Zemblan narrative imposed onto him by the second figure Kinbote who is in desperate need of remaining alive through his discourse. According to McHale's theory, in such a text, death is equal to silence: "death for each character is equated with the end of her or his story" (1987, p. 229). Shade composes the cantos and then Kinbote continues the narration by commenting on them to extend his narration. Kinbote's story holds many events that require re-reading of readers to be interpreted. As long as there are complex comments and the reading takes place and new interpretations are aroused, the narrative has the potentiality to ensure Kinbote's survival. Kinbote, by making the commentary complicated and open to different layers of interpretation and discovery, hopes to keep his reader active, excited and involved in the continuation of his own narrative.

\section{CONCLUSION}

In contrast with Shade who tries to play with life and death privately, Kinbote attempts to "translate private fate into public significance." For Kinbote "personal failures are the result of carefully planned human conspiracies, and death is the relentlessly advancing assassin, Gradus" (Maddox, 2009, p. 19). The fear Kinbote feels, and the obsession with the thought of the end of his narrative or death meaning Gradus's appearance and shooting the right person, make him more eager in enthroning himself somewhere like Shade's poem rather than wanting to make a place for himself in the poem. Therefore, what he has to do is either kill himself to end every disturbance and trauma he is exposed to or continue narrating to extend the span of his art and the existence of his own self. An egotistic character like Kinbote will continue narrating and projecting his image in the discourse to evade silence, as long as he can, and evade appearance of a second Gradus. It is “in Kinbote hands [that] Shade's poem becomes a coded key to the wonders of an imagined world” (Maddox, 2009, p. 17).

\section{REFERENCES}

[1] Belletto, S. (2006). "The Zemblan Who Came in from the Cold, or Nabokov's Pale Fire, Chance, the Cold War" ELH, Academic Research Library, 73(3), 755-780.

[2] Boyd, B. (1999). Nabokov's Pale Fire: The Magic of Artistic Discovery. Princeton: Princeton University Press.

[3] Boyd, M. (1983). The Reflexive Novel: Fiction as Critique. London: Associated University Press.

[4] Clark, T. (2002). Martin Heidegger. London: Routledge.

[5] Connely, J. M. (2005). The Cambridge Companion to Nabokov. Cambridge: Cambridge University Press.

[6] Foucault, M. (2000). "What is an author?" In David Lodge and Nigel Wood (Eds.), Modern Criticism and Theory: A Reader (pp. 183-187). Essex: Longman.

[7] Hofstadter, D. R. (1980). Godel, Escher, Bach: An Eternal Golden Braid, Harmondsworth: Penguin. 
[8] Hutcheon, L. (1983). “The Carnivalesque and Contemporary Narrative: Popular Culture and the Erotic," University of Ottawa Quarterly. 5, (1), 108-130.

[9] Maddox, L. (2009). Nabokov's Novels in English. Georgia: University of Georgia Press.

[10] McHale, B. (1987). Postmodernist Fiction. New York: Methuen.

[11] Morris, P. D. (2010). Vladimir Nabokov: Poetry and the Lyric Voice. Toronto: University of Toronto Press.

[12] Nobokov, V. (1973). Pale Fire. United States: Penguin Book.

[13] Ong, W. J. (1977). "Maranatha: death and life in the text of the book," In Interfaces of the Word: Studies in the Evolution of Consciousness and Culture, Ithaca: Cornell University Press.

[14] Pifer, E. (2003). Vladimir Nabokov's Lolita: A Casebook. Oxford: Oxford University Press.

[15] Reading, A. (2006). "Vulgarity's Ironist: New Criticism, Midcult, and Nabokov's Pale Fire," The Arizona Quarterly, 62, (2), Academic Research Library, 77-98.

[16] Sharpe, M. E. (1999). Russian Postmodernist Fiction: Dialogue with Chaos. New York: Mark Noumuch Lipvetsky.

[17] Sukenick, R. (1969). "The Death of the Novel," In The Death of the Novel and Other Stories, New York: The Dial Press.

[18] Waugh, P. (1992). Practising Postmodernism Reading Modernism. London: Edward Arnold.

[19] Waugh, P. (1984). Metafiction: The Theory and Practice of Self-conscious Fiction. London: Routledge.

Pyeaam Abbasi has received his B. A. in English Literature from the University of Isfahan in 2000, his M. A. in English Literature from Shiraz University in 2002, and his Ph. D. in English Literature from University of Shiraz in 2011. He is currently assistant professor of English literature teaching at the University of Isfahan, Iran.

Omid Amani is M. A. student of English Literature at the University of Isfahan, Iran. He has received his B. A. in English Literature from Semnan University, Iran in 2010. He has published two other essays in Studies in Literature and Language. The first one is "Margaret Atwood's Surfacing as a Critique of The Enlightenment Reason" which involved collaboration with Hossein Pirnajmuddin (Ph.D.) and the second one is "Atwood's Female Writing: A Reading of "This is a Photograph of Me"" that involved collaboration with Pyeaam Abbasi (Ph. D.). 